\section{The laryngeal mask airway and prolonged balanced regional anaesthesia}

\author{
J. Brimacombe MB ChB FRCAnaes, ${ }^{*}$ \\ N. Shorney MB BS FRCAnaes $\dagger$
}

The purpose of this paper is to report an eight-hour operation in which anaesthesia was provided by a combination of continuous epidural analgesia and light general anaesthesia administered via a laryngeal mask. During the perioperative period, the respiratory system was monitored with arterial blood gas and thoraco-abdominal movement analyses. There was no deterioration in respiratory function nor evidence of respiratory fatigue. We suggest that this is a suitable technique in fasting healthy patients undergoing prolonged surgery to the extremities.

Cette observation décrit une intervention de huit heures au cours de laquelle on a exécuté une analgésie péridurale continue associée à une anesthésie générale légère administrée par masque laryngé. Pendant l'intervention, le système respiratoire a été monitorisé par les gaz artériels et l'analyse de la mobilité thoraco-abdominale. Il n'y a pas eu de détérioration de la fonction respiratoire, ni d'évidence de fatigue respiratoire. Nous suggérons que cette technique convient à des patients non tarés et gardés à jeun pour une chirurgie prolongée des extrémités.

Prolonged anaesthesia is commonly regarded as an indication for tracheal intubation and pulmonary ventilation, ${ }^{1,2}$ although there is little evidence to support this. The reasons given are that intubation secures the airway and ventilation prevents respiratory fatigue and failure. Intubation and ventilation, however, carry considerable morbidity ${ }^{3-5}$ and can often be avoided.

\section{Key words}

ANAESTHETIC TECHNIQUES: balanced, endotracheal, epidural;

EQUIPMENT: masks, LMA.

From the $\dagger$ Department of Anaesthesia and Intensive Care,

Cairns Base Hospital, Cairns, Australia 4870; and

*Department of Anaesthesia, Royal Perth Hospital, Perth, Australia 6001.

Address correspondence to: Dr. J. Brimacombe, Department of Anaesthetics, Royal Perth Hospital, Perth 6001, Australia.

Accepted for publication 17th December 1992.
The feasibility of prolonged spontaneous ventilation anaesthesia has increased because of improvements in clinical monitoring. Respiratory failure and fatigue can be detected and appropriate measures taken. ${ }^{6}$ As a result, intubation may be indicated only to obtain a secure airway rather than to facilitate ventilation.

The laryngeal mask airway (LMA) may further facilitate prolonged spontaneous ventilation anaesthesia because it provides an effortless clear airway whilst avoiding the hazards of intubation and the use of neuromuscular blocking drugs. ${ }^{7}$ Also when used as part of a balanced regional technique with spontaneous ventilation, the LMA may permit a lighter level of anaesthesia than the endotracheal tube (ETT), hence reducing exposure to the volatile agent. ${ }^{8}$ In addition, it has been suggested that the LMA may be preferable to an ETT since it allows more normal physiology to be maintained. ${ }^{7,9,10}$ During spontaneous ventilation, glottic opening and closing can occur and the ciliary tree is not disrupted. Also, the LMA imposes less resistance and requires less additional inspiratory work than the corresponding sized ETT."

We report a case of an eight-hour lower limb procedure in which the patient breathed spontaneously through the LMA, as part of a balanced regional technique, ${ }^{12}$ to illustrate that such cases can be managed satisfactorily.

\section{Case report}

A 36-yr-old man, height $178 \mathrm{~cm}$, weight $82 \mathrm{~kg}$, presented for a free fibular transfer following a motorcycle accident five months previously. He was a heavy smoker, but had no other important past medical history. The procedure was estimated to take eight hours and pre-medication was not administered. The patient stopped smoking ten hours before the operation.

The patient received chest physiotherapy preoperatively and an epidural catheter was inserted at $\mathrm{L}_{2 / 3}$. Using 15 $\mathrm{ml}$ bupivacaine $0.5 \%$ a block was established to the level of $T_{9}$ after $30 \mathrm{~min}$ and anaesthesia was then induced with propofol, $200 \mathrm{mg}$. A size 4 LMA was inserted easily, the cuff inflated with $35 \mathrm{ml}$ air and anaesthesia was maintained with oxygen $33 \%$, nitrous oxide $66 \%$ and isoflurane $1 \%$ mixture through a circle system and absorber 
TABLE 1 Respiratory pattern analysis data derived from the extensometers (Mean \pm SD.

\begin{tabular}{|c|c|c|c|c|c|c|}
\hline $\begin{array}{l}\text { Time } \\
(h r)\end{array}$ & $\begin{array}{l}R R \\
\text { min }^{-1}\end{array}$ & $\begin{array}{l}V T c^{2} \\
m l\end{array}$ & $R C / A B^{3}$ & $\begin{array}{l}M C A / \\
V T c^{4}\end{array}$ & $T i / T t^{5}$ & $\begin{array}{l}V T c / T^{6} \\
L \cdot \sec ^{-1}\end{array}$ \\
\hline Pre & $\begin{array}{l}15.4 \\
(0.46)\end{array}$ & $\begin{array}{l}510 \\
(15)\end{array}$ & $\begin{array}{l}0.46 \\
(0.03)\end{array}$ & $\begin{array}{l}1.08 \\
(0.06)\end{array}$ & $\begin{array}{l}0.422 \\
(0.02)\end{array}$ & $\begin{array}{l}0.31 \\
(0.001)\end{array}$ \\
\hline 1 & $\begin{array}{l}14.6 \\
(0.14)\end{array}$ & $\begin{array}{l}385 \\
\text { (11) }\end{array}$ & $\begin{array}{l}0.34 \\
(0.012)\end{array}$ & $\begin{array}{l}1.07 \\
(0.36)\end{array}$ & $\begin{array}{l}0.436 \\
(.004)\end{array}$ & $\begin{array}{l}0.21 \\
(0.0057)\end{array}$ \\
\hline 2 & $\begin{array}{l}17.0 \\
(0.3)\end{array}$ & $\begin{array}{l}440 \\
(16)\end{array}$ & $\begin{array}{l}0.27 \\
(0.01)\end{array}$ & $\begin{array}{l}1.127 \\
(0.57)\end{array}$ & $\begin{array}{l}0.49 \\
(0.007)\end{array}$ & $\begin{array}{l}0.25 \\
(0.001)\end{array}$ \\
\hline 3 & $\begin{array}{l}16.5 \\
(0.7)\end{array}$ & $\begin{array}{l}447 \\
\text { (11) }\end{array}$ & $\begin{array}{l}0.17 \\
(0.007)\end{array}$ & $\begin{array}{l}1.06 \\
(0.48)\end{array}$ & $\begin{array}{l}0.439 \\
(0.025)\end{array}$ & $\begin{array}{l}0.28 \\
(0.0026)\end{array}$ \\
\hline 4 & $\begin{array}{l}23.0 \\
(0.6)\end{array}$ & $\begin{array}{l}464 \\
(17)\end{array}$ & $\begin{array}{l}0.36 \\
(0.039)\end{array}$ & $\begin{array}{l}1.255 \\
(0.07)\end{array}$ & $\begin{array}{l}0.502 \\
(0.013)\end{array}$ & $\begin{array}{l}0.36 \\
(0.0015)\end{array}$ \\
\hline 5 & $\begin{array}{l}22.3 \\
(1.4)\end{array}$ & $\begin{array}{l}520 \\
(10)\end{array}$ & $\begin{array}{l}0.355 \\
(0.046)\end{array}$ & $\begin{array}{l}1.23 \\
(0.032)\end{array}$ & $\begin{array}{l}0.477 \\
(0.017)\end{array}$ & $\begin{array}{l}0.41 \\
(0.0036)\end{array}$ \\
\hline 6 & $\begin{array}{l}23.0 \\
(0.9)\end{array}$ & $\begin{array}{l}551 \\
(19)\end{array}$ & $\begin{array}{l}0.339 \\
(0.032)\end{array}$ & $\begin{array}{l}1.196 \\
(0.049)\end{array}$ & $\begin{array}{l}0.493 \\
(0.01)\end{array}$ & $\begin{array}{l}0.442 \\
(0.001)\end{array}$ \\
\hline 7 & $\begin{array}{l}23.8 \\
(1.7)\end{array}$ & $\begin{array}{l}492 \\
(14)\end{array}$ & $\begin{array}{l}0.308 \\
(0.015)\end{array}$ & $\begin{array}{l}1.198 \\
(0.055)\end{array}$ & $\begin{array}{l}0.498 \\
(0.014)\end{array}$ & $\begin{array}{l}0.39 \\
(0.0027)\end{array}$ \\
\hline 8 & $\begin{array}{l}23.1 \\
(0.8)\end{array}$ & $\begin{array}{l}410 \\
(26)\end{array}$ & $\begin{array}{l}0.283 \\
(0.013)\end{array}$ & $\begin{array}{l}1.156 \\
(0.072)\end{array}$ & $\begin{array}{l}0.5 \\
(0.017)\end{array}$ & $\begin{array}{l}0.31 \\
(0.001)\end{array}$ \\
\hline Post & $\begin{array}{l}22.2 \\
(3.4)\end{array}$ & $\begin{array}{l}492 \\
(32)\end{array}$ & $\begin{array}{l}0.42 \\
(0.082)\end{array}$ & $\begin{array}{l}1.09 \\
(0.067)\end{array}$ & $\begin{array}{l}0.502 \\
(0.07)\end{array}$ & $\begin{array}{l}0.33 \\
(0.0025)\end{array}$ \\
\hline
\end{tabular}

${ }^{1}$ Respiratory rate (RR) (breaths $\cdot \min ^{-1}$ ).

${ }^{2}$ Calculated tidal volume VTc $(\mathrm{ml})$.

${ }^{3}$ Ratio of maximal ribcage/maximal abdominal movement ( $\left.\mathrm{RC} / \mathrm{AB}\right)$.

${ }^{4}$ Maximum compartmental amplitude/calculated tidal volume (MCA/VTc).

${ }^{5}$ Fractional inspiratory time $(\mathrm{Ti} / \mathrm{Tt})$.

${ }^{6}$ Mean inspiratory flow rate $(\mathrm{VTc} / \mathrm{Ti}) \mathrm{L} \cdot \mathrm{sec}^{-1}$.

with a fresh gas flow rate of $6 \mathrm{~L} \cdot \mathrm{min}^{-1}$. One hour after this, an epidural infusion was started at $8 \mathrm{ml} \cdot \mathrm{hr}^{-1}$ using plain bupivacaine $0.25 \%$. Opioid administration was avoided.

Perioperative monitoring consisted of: $\mathrm{FIO}_{2}, \mathrm{PETCO}_{2}$ (Datex Cardiocap 2), pulse oximetry, ECG, intra-arterial blood pressure monitoring, urine output and core temperature. Respiratory rate and spirometric tidal volume (VTsp) were recorded every five minutes (Ohmeda 5420 tidal volume monitor). Thoraco-abdominal movement was monitored with two extensometers placed about the chest and abdomen and linked to a data acquisition system. ${ }^{13-15}$ The change in chest and abdominal wall circumference and the computed sum of the two were recorded throughout the procedure (approximately 10,000 breaths). For logistical reasons only the waveforms of the first 40 breaths of each hour were analysed. The following data was derived for each breath: total inspiratory time (Ti), total expiratory time (Te), change in chest circumference (RC), abdominal circumference (AB) and chest plus abdominal wall circumference $(\mathrm{RC}+\mathrm{AB})$. From this information the following indices of respiratory func- tion were calculated: tidal volume (VTc), maximum compartmental amplitude/calculated tidal volume ratio (MCA/VTc), mean inspiratory flow (VTc/Ti), fractional inspiratory time (Ti/Tt), ratio maximal ribcage/abdominal wall movement and respiratory frequency. The results are given in Table I.

Fibreoptic laryngoscopy to the level of the mask apertures bars and arterial blood gas analysis were performed every hour. Initial fibreoptic laryngoscopy revealed the posterior surface of the epiglottis to be halfway down the mask aperture bars with a clear view of the cords and no visible oesophagus. This view did not change throughout the anaesthetic and respiratory obstruction did not occur. Changes in perioperative blood gases, VTsp and respiratory rate are shown in Table II. The increased respiratory rate during the last few hours matched the decrease in $\mathrm{PCO}_{2}$ and the slight increase in heart rate and may be explained by a reduction in block density as the anaesthetic wore off.

The procedure lasted for $8 \mathrm{hr} 15 \mathrm{~min}$. The LMA was removed under anaesthesia and $38 \mathrm{ml}$ of gas were aspirated from the cuff. Cuff pressures were not measured 
TABLE II Hourly perioperative arterial blood gases. Mean (SD) of tidal volume and respiratory rate calculated from data recorded every five minutes from tidal volume monitor

\begin{tabular}{|c|c|c|c|c|c|}
\hline $\begin{array}{l}\text { Time } \\
(h r)\end{array}$ & $p H$ & $\begin{array}{l}\mathrm{PCO}_{2} \\
m m \mathrm{Hg}^{2}\end{array}$ & $\begin{array}{l}\mathrm{PO}_{2} \\
m m \mathrm{Hg}\end{array}$ & $\begin{array}{l}\text { Respiratory } \\
\text { rate } \text { min }^{-1} \\
(S D)\end{array}$ & $\begin{array}{l}\text { Tidal } \\
\text { volume } \\
m l(S D)\end{array}$ \\
\hline 0 & 7.39 & 38 & 77 (air) & & \\
\hline 1 & 7.35 & 43.7 & 133 & $17(0.8)$ & $430(17)$ \\
\hline 2 & 7.34 & 41.6 & 119 & $17(0.7)$ & $440(50)$ \\
\hline 3 & 7.35 & 41.2 & 146 & $22(1.5)$ & $447(41)$ \\
\hline 4 & 7.38 & 39 & 152 & $23(1.6)$ & $475(21)$ \\
\hline 5 & 7.35 & 39 & 142 & $25(2.2)$ & $472(34)$ \\
\hline 6 & 7.37 & 37.2 & 157 & $24(2.7)$ & $453(23)$ \\
\hline 7 & 7.36 & 38.1 & 152 & $27(1.8)$ & $448(12)$ \\
\hline 8 & 7.36 & 37.2 & 142 & $24(1.9)$ & $440(15)$ \\
\hline 10 & 7.42 & 35 & 75 (air) & & \\
\hline
\end{tabular}

Time $0=$ pre-induction.

TABLE III Pre- and postoperative arterial blood gases and spirometry

\begin{tabular}{lllllll}
\hline Time & \multicolumn{7}{c}{$\begin{array}{c}\mathrm{PO}_{2} \\
\text { (air) }\end{array}$} & $\mathrm{PCO}_{2}$ & $\mathrm{BE}$ & $\begin{array}{l}F E V_{1} \\
L\end{array}$ & $\begin{array}{l}F V C \\
L\end{array}$ \\
\hline pre-op & 7.39 & 38 & 77 & -1 & 2.25 & 3.15 \\
2 hr post-op & 7.42 & 35 & 75 & -2 & 2.1 & 3.15 \\
14 hr post-op & 7.43 & 34.4 & 81 & -1 & 2.5 & 3.5 \\
26 hr post-op & 7.42 & 34.9 & 79 & -1.1 & 2.2 & 3.4 \\
\hline
\end{tabular}

during the procedure. Direct laryngoscopy revealed a normal laryngopharynx with no evidence of mucosal oedema or trauma. Within ten minutes of discontinuing isoflurane, the patient was awake and responsive. There was no shivering and he was comfortable with a sensory block to the level $\mathrm{T}_{10}$.

Spirometry and blood gas analysis were performed at 2, 14 and $26 \mathrm{hr}$ after surgery (Table III). The patient did not complain of a sore throat, had no obvious chest $x$-ray changes and his subsequent recovery was uneventful.

\section{Discussion}

Many patients cannot tolerate prolonged surgery under regional anaesthesia and may require either sedation or a general anaesthetic. ${ }^{12}$ Sedation places the patient at risk from respiratory depression and loss of airway patency. Intubation and ventilation may be associated with considerable morbidity, ${ }^{3-5}$ which is related to laryngoscopy, penetration of the vocal cords, the use of neuromuscular blocking drugs, and the physiological consequences of IPPV. Intubation and spontaneous ventilation may circumvent some of these problems, but may require deep anaesthesia to tolerate the presence of the ETT. ${ }^{8}$ Face mask anaesthesia is unsuitable since it does not provide a convenient secure airway. We suggest that the LMA offers an alternative technique for airway management during prolonged balanced regional anaesthesia.
There are three issues to consider with respect to the use of the LMA during prolonged anaesthesia with spontaneous ventilation: firstly, is respiratory function impaired in the perioperative period? Secondly, does the LMA damage the pharynx when in situ for prolonged periods? and finally, do the risks of aspiration in "fasting" patients increase during prolonged anaesthesia with the LMA?

Bendixen et al. suggested that there was progressive deterioration in respiratory function during spontaneous ventilation anaesthesia even during extremity surgery. ${ }^{16}$ In our patient there was no demonstrable deterioration in respiratory function or evidence of respiratory fatigue either during or after the procedure. In addition, data derived from the extensometer revealed no overall timerelated trends in thoraco-abdominal movement.

The position of the LMA remained constant throughout the procedure, as judged by fibreoptic laryngoscopy. We recommend fibreoptic laryngoscopy after placement and at regular intervals to verify the position of the LMA and to diagnose problems which may arise. ${ }^{17}$ The normal appearance of the pharynx and the absence of a sore throat on removal of the LMA suggests that the LMA did not damage the pharynx over this time, despite an increase in cuff gas volume which was presumably due to $\mathrm{N}_{2} \mathrm{O}$ diffusion and warming. ${ }^{18}$ Pharyngeal erythema has been reported following routine LMA anaesthesia, ${ }^{19}$ 
but there is no evidence that prolonged insertion increases the risk of pharyngeal trauma.

A cuffed ETT can guard against aspiration, although soiling may occur despite the presence of an inflated low pressure/high volume cuff. ${ }^{20,21}$ This patient was fasting and therefore the use of the LMA was considered appropriate. There are no published limits on the maximum duration that the LMA can remain in situ, but the use of the LMA for procedures lasting over six hours has been reported. ${ }^{22,23}$ Recurrent swallowing has occurred secondary to very light general anaesthesia, ${ }^{22}$ but no specific adverse effects have been attributed to the technique. In addition, several authors have incidentally noted the use of the LMA for between three and five hours and did not report any associated problems. ${ }^{10,24-26}$

It is not known if the risk of aspiration increases during prolonged anaesthesia with the LMA, but it would seem to be unlikely. Aspiration with the LMA is rare, ${ }^{9,27}$ often due to poor patient selection ${ }^{28-30}$ and tends to occur at induction or during recovery from anaesthesia. To date there have been no fatalities attributed to aspiration and the LMA. Two recent studies have suggested that the presence of an LMA may decrease barrier pressure and therefore increase the risk of aspiration, ${ }^{31,32}$ but these findings have been questioned ${ }^{33}$ and their clinical importance is unknown.

\section{Conclusion}

It is concluded that balanced regional anaesthesia via the LMA may be a suitable technique in "fasting" healthy patients undergoing surgery to the extremities. Its use in older patients or those with moderate systemic or respiratory disease is unclear. Further controlled comparative studies are required.

\section{References}

1 Fell $D$. The practical conduct of anaesthesia. In: Aitkenhead AR, Smith G (Eds.). Textbook of Anaesthesia. Edinburgh: Churchill Livingston, 1990: 349-62.

2 Nagi $H$, Brimacombe J. The LMA and swallowing. Anaesth Intensive Care 1992; 20: 116-7.

3 Harmer $M$. Complications of tracheal intubation. In: Latto IP, Rosen M (Eds.). Difficulties in Tracheal Intubation. London: Bailliere Tindall, 1987; 36-47.

4 Physiological aspects of controlled ventilation. In: Mushin WW, Rendell-Baker L, Thompson PW, Mapleson WW (Eds.). Automatic Ventilation of the Lungs. 3rd ed. London: Blackwell Scientific Publications, 1980; 1-32.

$5 \mathrm{Ng} W S$. Pathophysiological effects of tracheal intubation. In: Latto IP, Rosen M (Eds.). Difficulties in Tracheal Intubation. London: Bailliere Tindall, 1987; 12-35.

6 Sackner $M$, Krieger $B$. Non-invasive respiratory monitoring. In: Scharf SM, Cassidy S, (Eds.). Heart-lung Interac- tions in Health and Disease. New York: Marcel Dekker Inc, 1989: 663-805.

7 White $D C$. The laryngeal mask - a non-invasive airway. Eur J Anaesthesiol 1991; Supp 4: 1-4.

8 Wilkins CJ, Cramp PGW, Staples J, Stevens WC. Less anesthetic is required to tolerate a laryngeal mask airway than an endotracheal tube. Anesth Analg 1992; 74: S349.

9 Leach $A B$, Alexander $C A$. The laryngeal mask - an overview. Eur J Anaesthesiol 1991; Supp 4: 19-31.

10 Brain AIJ. The development of the laryngeal mask - a brief history of the invention, early clinical studies and experimental work from which the laryngeal mask evolved. Eur J Anaesthesiol 1991; Supp 4: 5-17.

11 Bhatt SB, Kendall AP, Lin ES, Oh TE. Resistance and additional inspiratory work imposed by the laryngeal mask airway. A comparison with tracheal tubes. Anaesthesia 1992; 47: 343-7.

12 Murdoch L, Rubin A. Use of the Brain laryngeal mask in balanced regional anaesthesia (Letter). Anaesthesia 1989; 44: 616.

13 Brimacombe J, MacFie A, McCrirrick A. The extensometer, potential applications in anaesthesia and intensive care. Anaesthesia 1991; 46: 756-61.

14 Brimacombe J, MacFie A, Masters A. The extensometer use in spontaneously ventilating awake volunteers. Anaesthesia 1992; 47: 872-7.

15 Brimacombe $J$. Non-invasive monitoring of tidal volume with an extensometer: laboratory and clinical studies. Anaesth Intensive Care (in press).

16 Bendixen HH, Bullwinkel B, Hedley-Whyte J, Laver MB. Atelectasis and shunting during spontaneous ventilation in anaesthetised patients. Anesthesiology 1964; 25: 297-301.

17 Brimacombe $J$. Laryngoscopy through the LMA - a useful skill to acquire (Letter). Anaesth Intensive Care 1992; 20: 535 .

18 Marjot $R$, Shaw DA, Fell $D$. Pressure exerted by the laryngeal mask airway upon the pharyngeal mucosa. $\mathrm{Br} \mathrm{J}$ Anaesth 1992; 68: 440-1P.

19 Harris TM, Johnson DF, Collins SRC, Heath ML. A new general anaesthetic technique for use in singers. Journal of Voice 1990; 4: 81-5.

20 Seegobin RD, van Hasselt GL. Aspiration beyond endotracheal cuffs. Can Anaesth Soc J 1986; 33: 273-9.

21 Spray SB, Zuidema GD, Cameron $J L$. Aspiration pneumonia. Incidence of aspiration with endotracheal tubes. Am J Surg 1976; 131: 701-3.

22 Brimacombe $J$. Laryngeal mask anaesthesia and recurrent swallowing. Anaesth Intensive Care 1991; 19: 275-6.

23 Brain AIJ. The Laryngeal Mask Instruction Manual. 1st Ed. Intavent January 1990.

24 Brain AIJ, McGhee TD, McAteer EJ, Thomas A, AbuSaad MAW, Bushman JA. The laryngeal mask airway. 
Development and preliminary trials of a new type of airway. Anaesthesia 1985; 40: 356-61.

25 Miranda AF, Reddy VG. Controlled ventilation with Brain laryngeal mask. Med Malaysia 1990; 45: 65-9.

26 Maltby $J R$, Loken $R G$, Watson NC. The laryngeal mask airway: clinical appraisal in 250 patients. Can J Anaesth 1991; 37: 509-13.

27 Brimacombe J, Berry A. Aspiration and the laryngeal mask airway - a survey of Australian intensive care units (Letter). Anaesth Intensive Care 1992; 20: 534-5.

28 Griffin RM, Hatcher IS. Aspiration pneumonia and the laryngeal mask airway. Anaesthesia 1990; 45: 1039-40.

29 Cyna AM, MacLeod DM. The laryngeal mask: cautionary tales. Anaesthesia 1990; 46: 167.

30 Nanji GM, Maltby $J R$. Vomiting and aspiration pneumonitis with the laryngeal mask airway. Can J Anaesth 1992; 39: 69-70.

31 Rabey PG, Murphy PJ, Langton JA, Barker P, Rowbotham $D J$. The effect of the laryngeal mask airway on lower oesophageal sphincter in patients during general anaesthesia. Br J Anaesth 1992; 69: 346-8.

32 Barker P, Murphy PJ, Langton JA, Rowbotham DJ. Regurgitation of gastric contents during general anaesthesia using the laryngeal mask airway. Br J Anaesth 1992; 69: 314-5.

33 Mikatti NE, Luthra AP, Healy TEJ, Mortimer AJ. Gastric regurgitation during general anaesthesia in the supine position with the laryngeal and face mask airway. $\mathrm{Br} \mathrm{J}$ Anaesth 1992; 69: 529-30P. 